\title{
GCU
}

Glasgow Caledonian

University

University for the Common Good

\section{Conservative interventions for urinary incontinence in women: an overview of Cochrane systematic reviews}

McClurg, Doreen; Pollock, Alex; Campbell, Pauline; Hazelton, Christine Roberta; Elders, Andrew; Hagen, Suzanne; Hill, David

Published in:

Cochrane Database of Systematic Reviews

DOI:

10.1002/14651858.CD012337

Publication date:

2016

Document Version

Publisher's PDF, also known as Version of record

Link to publication in ResearchOnline

Citation for published version (Harvard):

McClurg, D, Pollock, A, Campbell, P, Hazelton, CR, Elders, A, Hagen, S \& Hill, D 2016, 'Conservative

interventions for urinary incontinence in women: an overview of Cochrane systematic reviews', Cochrane

Database of Systematic Reviews, no. 9, CD012337. https://doi.org/10.1002/14651858.CD012337

\section{General rights}

Copyright and moral rights for the publications made accessible in the public portal are retained by the authors and/or other copyright owners and it is a condition of accessing publications that users recognise and abide by the legal requirements associated with these rights.

Take down policy

If you believe that this document breaches copyright please view our takedown policy at https://edshare.gcu.ac.uk/id/eprint/5179 for details

of how to contact us. 


\section{(E) Cochrane Library}

Cochrane Database of Systematic Reviews

\section{Conservative interventions for urinary incontinence in women: an Overview of Cochrane systematic reviews} (Protocol)

McClurg D, Pollock A, Campbell P, Hazelton C, Elders A, Hagen S, Hill DC

McClurg D, Pollock A, Campbell P, Hazelton C, Elders A, Hagen S, Hill DC.

Conservative interventions for urinary incontinence in women: an Overview of Cochrane systematic reviews.

Cochrane Database of Systematic Reviews 2016, Issue 9. Art. No.: CD012337.

DOI: 10.1002/14651858.CD012337.

www.cochranelibrary.com 
TABLE OF CONTENTS

HEADER . . . . . . . . . . . . . . . . . . . . . . . . . . . . . . . . . . . . . . . 1

ABSTRACT . . . . . . . . . . . . . . . . . . . . . . . . . . . . . . . . . . . . . . . 1

BACKGROUND . . . . . . . . . . . . . . . . . . . . . . . . . . . . . . . . . . . . . . . . . . . .

Figure 1. . . . . . . . . . . . . . . . . . . . . . . . . . . . . . . . . . . . . . .

OBJECTIVES . . . . . . . . . . . . . . . . . . . . . . . . . . . . . . . . . . . . . . . . . . . .

METHODS . . . . . . . . . . . . . . . . . . . . . . . . . . . . . . . . . . . . . . 8

ACKNOWLEDGEMENTS . . . . . . . . . . . . . . . . . . . . . . . . . . . . . . . . . . . . . . . .

REFERENCES . . . . . . . . . . . . . . . . . . . . . . . . . . . . . . . . . . . . . . 12

ADDITIONAL TABLES . . . . . . . . . . . . . . . . . . . . . . . . . . . . . . . . . . . . . .

APPENDICES . . . . . . . . . . . . . . . . . . . . . . . . . . . . . . . . . . . . . . . . . . .

CONTRIBUTIONS OF AUTHORS . . . . . . . . . . . . . . . . . . . . . . . . . . . . . . . . . . . . . . . .

DECLARATIONS OF INTEREST . . . . . . . . . . . . . . . . . . . . . . . . . . . . . . . . . . . .

SOURCES OF SUPPORT . . . . . . . . . . . . . . . . . . . . . . . . . . . . . . . . . . . . . . . . . . .

Conservative interventions for urinary incontinence in women: an Overview of Cochrane systematic reviews (Protocol)

Copyright $\odot 2016$ The Cochrane Collaboration. Published by John Wiley \& Sons, Ltd. 


\title{
[Overview of Reviews Protocol] \\ Conservative interventions for urinary incontinence in women: an Overview of Cochrane systematic reviews
}

\author{
Doreen McClurg ${ }^{1}$, Alex Pollock ${ }^{1}$, Pauline Campbell ${ }^{1}$, Christine Hazelton ${ }^{1}$, Andrew Elders ${ }^{1}$, Suzanne Hagen ${ }^{1}$, David C Hill $^{2}$ \\ ${ }^{1}$ Nursing, Midwifery and Allied Health Professions Research Unit, Glasgow Caledonian University, Glasgow, UK. ${ }^{2}$ NMAHP Research \\ Unit, University of Stirling, Stirling, UK \\ Contact address: Doreen McClurg, Nursing, Midwifery and Allied Health Professions Research Unit, Glasgow Caledonian University, \\ Cowcaddens Road, Glasgow, G4 0BA, UK. Doreen.McClurg@gcal.ac.uk.
}

Editorial group: Cochrane Incontinence Group.

Publication status and date: New, published in Issue 9, 2016.

Citation: McClurg D, Pollock A, Campbell P, Hazelton C, Elders A, Hagen S, Hill DC. Conservative interventions for urinary incontinence in women: an Overview of Cochrane systematic reviews. Cochrane Database of Systematic Reviews 2016, Issue 9. Art. No.: CD012337. DOI: 10.1002/14651858.CD012337.

Copyright (C) 2016 The Cochrane Collaboration. Published by John Wiley \& Sons, Ltd.

\begin{abstract}
A B S T R A C T
This is the protocol for a review and there is no abstract. The objectives are as follows:

To synthesise Cochrane reviews of conservative interventions, as described above, for the prevention or treatment of female urinary incontinence. Outcomes are described below.
\end{abstract}

\section{B A C K G R O U N D}

At least one-quarter of all adult women have urinary incontinence (UI), with prevalence increasing with age (Sandvik 2000). Around $20 \%$ of women with urinary problems seek professional help; this percentage increases with advancing age and is higher among women with other concomitant urogenital problems (Morrill 2007).

Evidence suggests that for the majority of women affected, UI impacts significantly on daily living. It has been shown to interfere with physical, psychological and social activities of women, reducing general health, wellbeing and quality of life (NICE 2013). It is associated with an increased prevalence of major depression (Melville 2009); and in older women is linked to social isolation and psychological distress (Bogner 2002). UI can cause a number of serious medical conditions, such as perineal rash, pressure ulcers and urinary tract infections and increases the risk of admission to long-term residential care (Hunskaar 2002). The annual cost to the NHS of treating clinically significant female UI has been estimated to be GBP 233 million (Perry 2000). This does not include the personal costs borne by the women affected, which have been estimated to be GBP 178 million (Turner 2004). UI is therefore prevalent and costly to healthcare providers; and to women both financially and in terms of physical and mental wellbeing.

Urinary incontinence can result from damage to the neural control of the bladder or the pelvic floor muscles, or from direct mechanical trauma to the pelvic floor (Glazener 2001). The risk is increased by vaginal (particularly assisted) delivery, increasing age and parity, obesity and the menopause (MacArthur 1993; Wilson 1996; Thom 1997). UI may also be caused by trauma or disease to the bladder.

Incidence figures depend on the definition used and the population investigated, with reported annual incidence rates (numbers of new cases) of urinary incontinence ranging from $1 \%$ to $11 \%$, and the annual remission rate from $6 \%$ to $11 \%$ (Hunskaar 2005). 


\section{Description of the condition}

Urinary incontinence (UI) is the involuntary loss of urine, and can be caused by a number of different conditions (Blaivas 1997; Haylen 2010).

Continence is achieved through an interplay of the normal anatomical and physiological properties of the bladder, urethra, sphincter and pelvic floor; and the nervous system co-ordinating these organs. The active relaxation of the bladder coupled by the ability of the urethra and sphincter to contain urine within the bladder by acting as a closure mechanism during filling, allow storage of urine until an appropriate time and place to void is reached. The role of the pelvic floor in providing support to the bladder and urethra, and allowing normal abdominal pressure transmission to the proximal urethra is also considered essential in the maintenance of continence. Crucial to the healthy functioning of the bladder, urethra, sphincter and pelvic floor is coordination between them, facilitated by an intact nervous system control. Incontinence occurs when this normal relationship between the lower urinary tract components is disrupted, resulting from nerve damage or direct mechanical trauma to the pelvic organs. Advancing age, higher parity, vaginal delivery, obesity and menopause are associated with an increase in risk (Rehman 2011).

There are three main types of UI:

1. Stress urinary incontinence (SUI): is the complaint of involuntary loss of urine on effort or physical exertion (e.g. sporting activities) (Haylen 2010). Stress UI is a symptom, rather than a condition. Research has shown that about $50 \%$ of the women below the age of 65 years with UI had stress UI (Milsom 2012).

2. Urgency urinary incontinence (UUI): is the complaint of involuntary loss of urine associated with urgency (Haylen 2010). Isolated UUI is the least common type, accounting for $10 \%$ of women who have UI (Milsom 2012).

3. Mixed urinary incontinence (MUI): is the complaint of involuntary loss of urine associated with urgency and also with effort or physical exertion or on sneezing or coughing (Haylen 2010). It occurs in around 30\% of women (Milsom 2012). In addition, loss of urine may occur:

- At night (nocturnal enuresis, the complaint of loss of urine occurring during sleep) or the interruption of sleep because of the need to urinate, with loss of urine if the toilet is not reached in time to void); and

- During intercourse (coital incontinence, the complaint of involuntary loss of urine with coitus, occurring with penetration or intromission, or at orgasm)

\section{Description of the interventions}

A wide range of interventions can be delivered in an attempt to reduce the symptoms of UI in women, including conservative, pharmacological and surgical interventions. Conservative interventions are generally recommended as the first line of treatment for women with UI (NICE 2013), and are therefore the focus of this overview. However we will include reviews in which the comparator intervention is a pharmacological, surgical or other management intervention. We will include reviews in which a single conservative intervention is delivered or in which two or more conservative interventions are delivered in combination.

The type of intervention selected for an individual woman will depend on an assessment of their symptoms, types of incontinence, factors contributing to UI, associated medical conditions, and clinician and individual choice.

\section{Conservative interventions}

Conservative management of UI largely comprises physical, behavioural and psychological interventions, often delivered in combination (French 2010), including (but not limited to) (see Figure $1)$ :

Conservative interventions for urinary incontinence in women: an Overview of Cochrane systematic reviews (Protocol) 
Figure I.

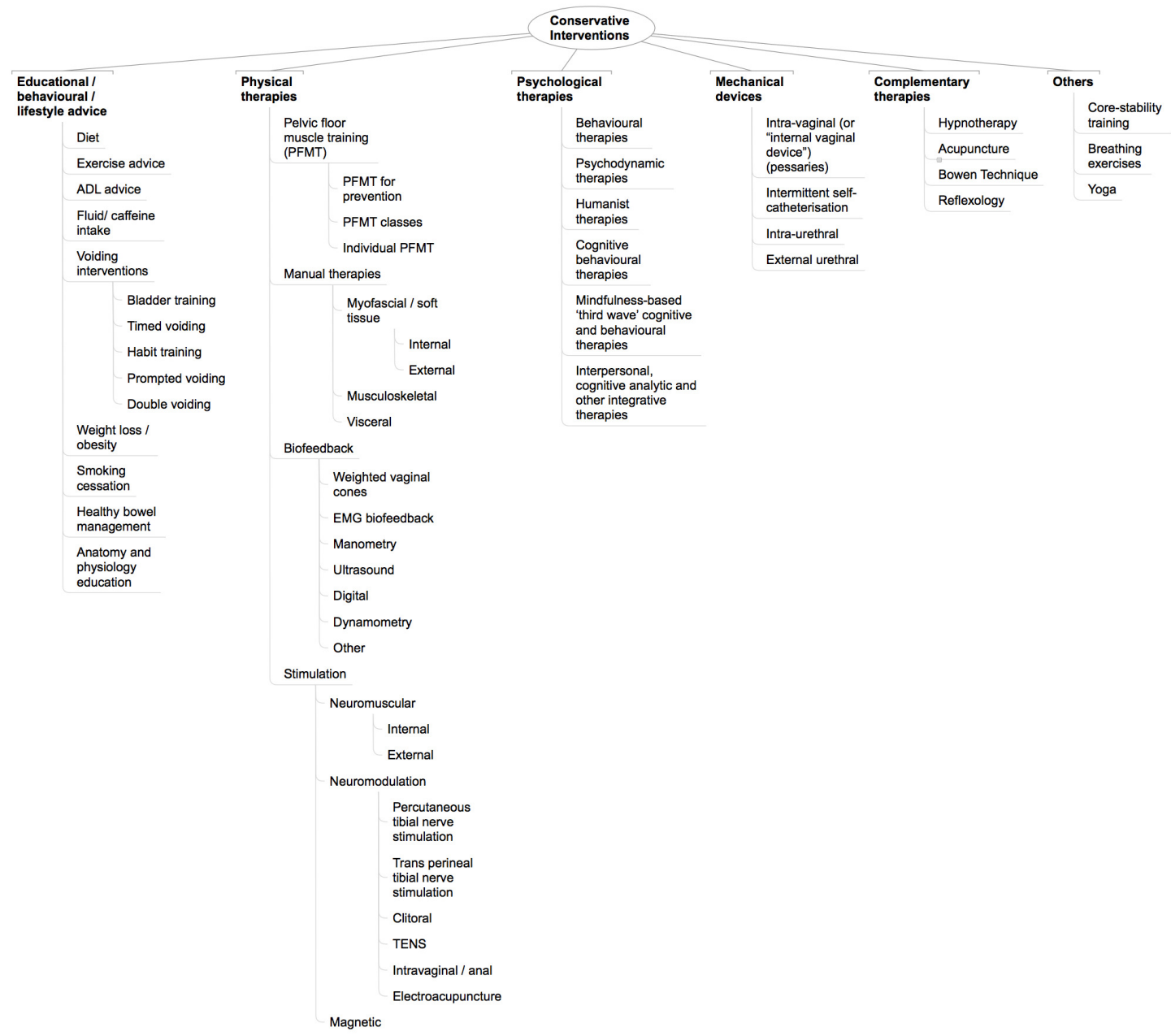

- Mechanical devices to prevent or reduce urinary leakage. These include pessaries (urethral and vaginal inserts) and mechanical plugs/patches (Lipp 2014).

- Physical therapies - for women with SUI the aim is to improve muscle control. This principally includes pelvic floor muscle training, which can be delivered with or without the use of assistive devices such as weighted vaginal cones, biofeedback or electrostimulation (Dumoulin 2014).

- Educational, behavioural and lifestyle advice to enhance management of urinary incontinence. These commonly include methods of toileting assistance, such as prompted voiding, habit/ bladder retraining and timed voiding (Eustice 2000;

Ostaszkiewicz 2004a; Ostaszkiewicz 2004b), and advice about lifestyle factors, such as weight loss, management of fluid intake, caffeine and alcohol intake and physical activity and exertion (Imamura 2015).
- Psychological interventions. A range of psychological therapies, based on a number of different philosophical or theoretical approaches, can be used to help a woman cope with her UI symptoms and improve her quality of life. These include the Health Belief Model (Chiarelli 1999); Theory of Planned Behaviour (Whitford 2011); and the Social Cognitive theory (Self-efficacy) (Alewijnse 2003a; Alewijnse 2003b).

- Complementary therapies. The Complementary Medicine Field of the Cochrane Collaboration defines complementary medicine as "practices and ideas which are outside the domain of conventional medicine in several countries" and which are defined by its users as "preventing or treating illness, or promoting health and wellbeing" (Smith 2006). Therapies which are considered complementary practices in one country or culture may be considered conventional in another. For the 
purpose of this overview, we define complementary therapies as complementary interventions, such as acupuncture/ electroacupuncture, reflexology, but excluding medicines or consumed remedies (i.e. excluding herbal medicines, traditional Chinese medicines, homeopathic remedies) (Bø 2013).

In addition to these groups of interventions, there are a growing number of digital health interventions which use new technologies and media to support and enhance the delivery of conservative management of UI. In particular, digital health interventions can help support the delivery of behavioural-based interventions, and may be used as part of bladder training or voiding programmes, or both; (see How the interventions might work for further description of types of conservative interventions within these categories). These conservative interventions are the focus of the Overview, and the following interventions will only be included if they are used as comparators in the included evidence.

\section{Pharmacological (drug) interventions}

A number of different pharmacological therapies have been investigated for the treatment of urinary incontinence, including

- oestrogen (Cody 2012)

- anticholinergic drugs (Rai 2012)

- adrenergic agents (Alhasso 2005) and

- botulinum toxin (Duthie 2011).

These interventions may have local or systemic effects.

\section{Surgical interventions}

Surgical procedures to remedy urinary incontinence generally aim to lift and support the urethrovesical junction. It has been identified that there is disagreement about the precise mechanisms achieved by surgery and that the choice of procedures is often influenced by a number of different factors, including co-existent problems, a surgeon's specialty and preference, and the physical features of the person affected (Glazener 2001). Surgical methods principally include

- open abdominal retropubic suspension (Lapitan 2016)

- laparoscopic retropubic suspension (Dean 2006)

- midurethral sling procedures (Ford 2015)

- traditional suburethral sling procedures (Rehman 2011)

- anterior vaginal repair (Glazener 2001)

- bladder neck needle suspensions (Glazener 2014)

- peri-urethral injections (Kirchin 2012)

- artificial sphincters (Islah 2013)

\section{Other interventions for UI}

In addition to these three groups of interventions, specialised products can be used in the management or treatment of UI.

These include special pads and bedsheets, as well as catheters, sheaths and bags.

\section{Investigation of UI}

There are a number of different techniques for the diagnosis of the cause of urinary incontinence, including urodynamic investigations (Clement 2013), diaries, pad tests (Groutz 2000), and imaging techniques such as $\mathrm{x}$-rays and ultrasound.

\section{How the intervention might work}

Conservative interventions can work in a variety of ways, and the mechanism of action may be mechanical, physical, behavioural or psychological, or a combination of these. For categories of conservative interventions, see Figure 1.

\section{Mechanical devices}

These are physical devices that are designed to stop or control urinary leakage. They can be inserted inside the vagina or urethra (internal placement) or applied to the external surface of the urethra (external placement) (Lipp 2014). These devices work in a number of different mechanical ways:

- Intravaginal (or 'internal vaginal device') (also known as pessaries): These devices are inserted into the vagina with the aim of supporting the bladder neck to improve stress urinary incontinence (SUI). Some devices are also shaped with a knob which compresses the urethra, which also helps to reduce SUI.

- Intra-urethral: This is a device that is inserted into the urethra acting like a plug to prevent leakage. It is inserted and removed by the individual as required.

- External urethral: This is a device that is applied like a seal to the outer surface of the urethral opening (external placement) to stop leakage of urine from the urethra.

\section{Physical therapies}

Physical therapies are provided by rehabilitation professionals, using specially designed exercises, delivered with or without the use of assistive devices, to help individuals regain or improve physical control of their bladder. These

- Pelvic floor muscle training involves repetitive selective voluntary contraction and relaxation of specific pelvic floor muscles. PFMT exercises can be taught to women by rehabilitation professionals, but then are carried out independently by the woman on a regular basis, with or without supervision. PFMT can improve the strength, endurance and coordination of these muscles (Alves 2015; Dumoulin 2014). For those with UUI the biological rationale is based on Godec's observation that a detrusor muscle contraction can be inhibited by a pelvic floor muscle contraction induced by electrical stimulations (Godec 1975). Further de Groat 1997 demonstrated that during urine storage there is an increased pudendal nerve outflow response to the external urethral sphincter increasing intraurethral pressure and representing what he termed a "guarding reflex" for incontinence (de Groat 1997; 
de Groat 2001). Additionally, Morrison 1995 demonstrated that Barrington's micturition centre excitatory loop switches on when bladder pressures are between 5 to $25 \mathrm{mmHg}$, while the inhibitory loop is predominantly active above $25 \mathrm{mmHg}$. Inhibition involves an automatic (unconscious) increase in tone for both the pelvic floor muscle and the urethral striated muscle. Thus, voluntary pelvic floor muscle contractions may be used to control UUI. After inhibiting the urgency to void and the detrusor contraction, the woman can reach the toilet in time to avoid urine leakage.

- Biofeedback is a technique used to supplement or enhance PFMT. Information about a normally unconscious physiological process is presented to the individual and the therapist as a visual, auditory or tactile signal (Sandweiss 1985). Such feedback enables a person to identify and modify a bodily function of which they may be unaware. Typically this may involve digital palpation or the use of a device to record the biological signals (e.g. squeeze pressure, electrical activity, pelvic floor morphometry using ultrasound) during a voluntary pelvic floor muscle contraction and presentation of this information back to the woman in auditory or visual form. Examples of this feedback are verbal encouragement, a louder sound with a stronger squeeze or an increasing number of lights on a visual display as the strength of the squeeze increases, and visual display of levator ani contraction on an ultrasound screen. Thus for a muscle that cannot be seen, unlike for example the quadriceps muscles of the knee, the women receives some sort of signal about their ability to use their pelvic floor muscle. Biofeedback may also be provided by the use of weighted vaginal cones, which are small weights placed in the vagina which require contraction of the pelvic floor muscle to prevent them from slipping out. The cones provide a form of biofeedback as the sensation of one slipping out induces a pelvic floor muscle contraction which may both strengthen muscles and help to synchronize muscle contraction with increases in abdominal pressure (Herbison 2013)

- Stimulation A number of different types of stimulation, including electrical and magnetic stimulation, can be delivered through either surface electrodes (transcutaneous) or via direct stimulation (percutaneous) with the aim of stimulating the nerve supply and altering nerve activity. Stimulation of nerve supply is thought to improve muscle tone and sensation of the pelvic floor muscles, enhancing muscle control; and it also aims to reduce detrusor contraction in the case of UUI. Electrical stimulation therapy can be used to treat overactive bladder via different routes, such as implantable or internal electrodes (sacral neuromodulation) and non-implantable or external electrodes. The latter can be sub-classified as endocavitary electrodes (rectal or intravaginal) or percutaneous electrodes (tibial nerve stimulation). Cadwell 1963 was the first to report the use of intravaginal electrical stimulation (IES) in the treatment of urinary incontinence. Subsequently, Messelink 1999 also used it with satisfactory results. IES using frequencies below $12 \mathrm{~Hz}$ stimulates the pudendal nerve, which may inhibit the detrusor muscle, reduce involuntary contractions and, consequently, reduce the number of micturitions in 24 hours (Messelink 1999). Electrical stimulation also works in a passive way, helping women to become conscious of the perineal muscle contraction and this may, in turn, help to inhibit detrusor involuntary contractions (Amaro 2003). IES can be used on its own or in association with pelvic floor muscle exercises, often indicated in SUI and OAB. Percutaneous tibial nerve stimulation (PTNS) is a form of neuromodulation that delivers retrograde stimulation to the sacral nerve plexus through percutaneous electrical stimulation of the posterior tibial nerve via a needle electrode inserted cephalad to the medial malleolus, an anatomical area recognized as the bladder centre (Hajebrahimi 2015).

- Magnetic stimulation appears to induce inhibitory effects on detrusor overactivity in a similar manner to electrical stimulation, with the significant clinical advantage of being noninvasive (Takahashi 2003).

- Bladder training encourages people to extend the time between voiding so that continence might be regained. This can take months to achieve but may help people who are physically and mentally able to use this method. For those with UUI the biological rationale is based on Godec's observation that a detrusor muscle contraction can be inhibited by a pelvic floor muscle contraction induced by electrical stimulation (Godec 1975). Further de Groat 1997 demonstrated that during urine storage there is an increased pudendal nerve outflow response to the external urethral sphincter increasing intraurethral pressure and representing what he termed a "guarding reflex" for incontinence (de Groat 1997; de Groat 2001). Additionally, Morrison 1995 demonstrated that Barrington's micturition centre excitatory loop switches on when bladder pressures are between 5 to $25 \mathrm{mmHg}$, while the inhibitory loop is predominantly active above $25 \mathrm{mmHg}$. Inhibition involves an automatic (unconscious) increase in tone for both the pelvic floor muscle and the urethral striated muscle. Thus, voluntary pelvic floor muscle contractions may be used to control UUI. After inhibiting the urgency to void and the detrusor contraction, the woman can reach the toilet in time to avoid urine leakage (Wallace 2004)

- Manual therapy is defined as a clinical physical approach utilizing specific hands-on techniques. It may include massage, soft tissue mobilization, various connective tissue techniques, myofascial release, mobilization of joints, joint manipulation or mobilization of nerve tissue. It is used to diagnose and treat soft tissues and joint structures for the purpose of modulating pain; increasing range of motion; reducing soft tissue oedema; inducing relaxation; improving contractile and non-contractile tissue extensibility, and/or stability; facilitating movement; and improving function (Personal Communication: Bø 2016). 
In addition to these groups of interventions, there are a growing number of digital health interventions which use new technologies and media to support and enhance the delivery of conservative management of UI. In particular, digital health interventions can help support the delivery of behavioural-based interventions, and may be used as part of bladder training or voiding programmes.

\section{Educational, behavioural and lifestyle advice}

Several lifestyle factors are thought to play a role either in the onset or later in the resolution or management of UI. These include:

- Diet: many dietary factors are thought to aggravate urinary urgency, and may also relate to weight gain or constipation, or both (see below). Dietary advice can therefore be beneficial to the management of UI (Imamura 2015).

- Exercise and activities of daily living (ADL) advice: weakened pelvic floor support structures and raised intraabdominal pressure caused by heavy lifting and strenuous activity may result in UI. Strenuous activity alone may also increase incontinence in the short term. Appropriate advice can help women to manage the impact of exercise and daily physical activity on UI, whilst maintaining a healthy lifestyle (Bø 2013).

- Fluid/caffeine intake: worsening of urinary urgency, frequency and incontinence is often reported after consuming caffeine, alcohol, fizzy drinks, sweetened diet drinks or excessive fluids. Caffeine can increase bladder muscle contractility, whereas alcohol or excessive fluids may have a diuretic effect (Imamura 2015) .

- Voiding interventions: this is a broad term which is used to describe any type of scheduled toileting intervention, which can include programmes of scheduled bladder voiding and bladder training (aimed at trying to correct faulty habit patterns of frequent urination (if present), improve control over bladder urgency, prolong voiding intervals, increase bladder capacity, reduce incontinent episodes, and restore women's confidence in controlling bladder function) (Eustice 2000).

- Weight loss/obesity: obesity and urinary incontinence are common problems in women. Obese women have higher intraabdominal pressure than non-obese women, and it is thought that this chronically elevated pressure may predispose to incontinence in two ways: firstly by weakening pelvic floor support structures; and secondly by raising the intra-abdominal pressure (Imamura 2015) .

- Smoking cessation: there is evidence of a relationship between cigarette smoking and UI, although the mechanism is not fully understood (Bump 1992). Chronic coughing among smokers may also contribute to UI by raising intra-abdominal pressure (Imamura 2015) .

- Healthy bowel management: constipation can obstruct the bladder, preventing adequate voiding and resulting in urine leakage. Chronic straining may also be a risk factor in the development of UI. Advice which avoids or limits constipation or chronic straining may improve or prevent UI (Imamura 2015) .

- Anatomy and physiology education: educational interventions to teach women about the causes of their UI may improve understanding of the condition and may therefore help women manage their symptoms (Imamura 2015).

\section{Psychological therapies}

There are many different types of psychological therapies, which are based on a range of theoretical and philosophical standpoints. These are often forms of talking therapy, with individuals or in groups, but may also include interventions such as telephone or internet-based support. Psychological therapies are generally aimed at helping people change the way they think and behave. Psychological therapies may help women with UI to manage and maintain a sense of wellbeing and enhance quality of life. For the purposes of this overview we will consider psychological therapies within the categories proposed and described by Shinohara 2013, as follows:

- Behavioural therapies: this includes behavioural therapy, behavioural activation, social skills training/assertiveness training, and relaxation therapy.

- Cognitive-behavioural therapies: this includes cognitive therapy, rational emotive behavioural therapy, problem-solving therapy, self-control therapy, and courses aimed at coping with depression.

- Mindfulness-based 'third wave' cognitive and behavioural therapies: this includes acceptance and commitment therapy, compassionate mind training, functional analytical psychotherapy, extended behavioural activation, metacognitive therapy, mindfulness-based cognitive therapy, and dialectical behavioural therapy.

- Psychodynamic therapies: this includes interventions based on Drive/structural model, Relational model, and Integrative analytical model.

- Humanist therapies: this includes Person-centred therapy, Gestalt therapy, experiential therapies, transactional analysis, existential therapy, and non-directive/supportive therapies.

- Interpersonal, cognitive analytic and other integrative therapies: this includes interpersonal therapy, cognitive-analytic therapy, psychodynamic-interpersonal therapy, cognitivebehavioural analysis system of psychotherapy, counselling, and motivational interviewing.

\section{Complementary therapies}

A number of different alternative therapies, such as hypnotherapy and acupuncture, may be used, often alongside other conservative interventions. These interventions are generally provided to help people feel better and to promote health and wellbeing. Complementary therapies used to reduce symptoms and promote wellbeing in women with UI may include (but are not limited to): 
- Acupuncture/Electroacupuncture: this is the practice of inserting a needle or needles into certain points in the body for therapeutic purposes (Wang 2013).

- Hypnotherapy: this is a form of psychotherapy that can be used to create subconscious change in an individual in the form of new responses, thoughts, attitudes, behaviours or feelings (Komesu 2011).

- Bowen Technique: this is a hands-on therapy in which very gentle pressure is applied to specific points on the body (Wilks 2007) .

- Reflexology: is a massage used to relieve tension and treat illness, based on the theory that there are reflex points on the feet, hands, and head linked to every part of the body (Yau 2006).

\section{Other conservative interventions}

There are a number of other conservative interventions which may be used for women with UI, which do not fit within the above categories. These can include (but are not limited to):

- Core-stability training: specific exercises, comprising stretching and strengthening exercises which are adapted to the condition of the intervention, aimed at improving muscle strength and control around the pelvic area. These exercises may be delivered by an exercise instructor or person who is not a rehabilitation professional. Increased muscle strength and control around the pelvic area may improve the symptoms of UI by changing intra-abdominal pressure and increasing pelvic floor muscle control (Bø 2013).

- Breathing exercises/Hypopressive exercise: breathing exercises generally aim to complement PFMT by changing the pressure on the abdominal wall and improving the overall quality of pelvic floor muscle training exercises (Bø 2013).

- Pilates: modern Pilates exercise programmes incorporate exercises that involve breathing and contraction of pelvic floor muscles. The pelvic floor muscles are not specifically trained, but pelvic floor muscles are trained incidentally during exercise and movement. The co-contraction of pelvic floor muscles that occurs incidentally during Pilates exercises will counteract increases in intra-abdominal pressure that occur during exercise, preventing leakage and strengthening pelvic floor muscles (Bø 2013).

- Yoga: a physical, mental and spiritual practice, which may benefit UI through changes to physical (e.g. muscle stretching, control) and psychological mechanisms (Bø 2013).

- Paula Method: all sphincters in the body work simultaneously so exercising the ring muscles of the mouth, eyes, or nose may result in co-contraction and strengthening of the pelvic floor muscles (Bø 2013).

- Tai Chi: Tai Chi is an ancient exercise regimen originating in China and has widespread use as exercise for general health in China. Chang 1986 describes an exercise called

- 'the deer' involving contraction of the anal sphincter. The exercise is recommended for both men and women for conditions related to the pelvic area (Bø 2013).

- Posture: Theory: Carriere 2006 has claimed that "poor posture" can lead to pain and dysfunction in the pelvic floor. It is thought that optimal strategies for transferring loads will balance control of movement while maintaining optimal joint axes, maintain sufficient intra-abdominal pressure without compromising the organs (preserve continence, prevent prolapse or herniation) and support respiration. Non-optimal strategies for posture, movement and breathing, or combinations thereof, create failed load transfer which can lead to pain, incontinence and breathing disorders (Bø 2013).

\section{Why it is important to do this overview}

Conservative management is recommended as a first line of treatment for women with UI (NICE 2013). They often have complex aetiologies and co-morbid conditions and identifying the most effective rehabilitation interventions is not always easy. Given the importance of curing, improving or managing UI symptoms to allow women to have an active lifestyle and good quality of life, there are a substantive and growing number of randomised controlled trials (RCTs) and systematic reviews relating to the effectiveness of conservative interventions for UI. Despite this growing body of evidence, current clinical practice often does not reflect the available increasing evidence-base. This important area of practice receives little attention in undergraduate physiotherapy education, for example, less than 2 hours in the UK (McClurg 2013), and is largely driven by post-graduate courses and peer support in Canada (Francis 2012). Lack of sufficient time to identify and synthesise evidence is cited as the key barrier to evidence-utilisation within UI rehabilitation (McClurg 2013).

It has been recognised that a large and growing body of systematic reviews can be overwhelming for decision makers, and health-care practitioners do not have time to keep up to date with this evidence-base (Bastian 2010). The Cochrane Incontinence Group has (in December 2015) 107 reviews and protocols relating to urinary incontinence, of which 55 are related to mechanical, physical, psychological or educational interventions for the treatment or prevention of urinary incontinence (CIG 2015). This large number of Cochrane reviews may be overwhelming for healthcare practitioners seeking best evidence relating to conservative interventions for urinary incontinence, and create a barrier to evidencebased practice. It is therefore important to bring all Cochrane reviews relating to conservative interventions for the prevention or treatment of female urinary incontinence together, in order to signpost clinical decision makers to best evidence and support efficient use of best evidence.

Furthermore, while Cochrane reviews synthesise available RCT evidence relating to UI in women, these Cochrane reviews often explore the effects of specific single interventions compared to placebo or control interventions. However, in clinical practice, the 
choice will be generally be between a variety of interventions (or a combination) rather than an all-or-nothing choice of using or not using one of the interventions. Thus the synthesis of evidence relating to single, specific UI interventions fails to facilitate translation of evidence into clinical practice or decision making. A Cochrane overview of conservative interventions for women with UI will synthesise into one accessible, comprehensive document all high quality evidence about UI conservative interventions, assess the limitations of current best evidence and enable indirect comparisons of the effects of different interventions on UI. This proposed overview will support evidence-based management of UI amongst key decision makers (such as clinicians, policy makers, or informed health service users) and educators of Allied Health Professionals.

\section{O B J E C T I V E S}

To synthesise Cochrane reviews of conservative interventions, as described above, for the prevention or treatment of female urinary incontinence. Outcomes are described below.

\section{METHODS}

\section{Criteria for considering reviews for inclusion}

We will include any Cochrane review that meets the following criteria:

Participants: Reviews of studies in which the participants are female adults ( $\geq 18$ years) with a clinical diagnosis of UI, regardless of cause or comorbidities, and including stress, urge or mixed UI. Interventions: Reviews of studies which investigate a conservative intervention for which the primary aim is to prevent, improve or cure UI. Conservative interventions include those listed in How the interventions might work, and are illustrated in Figure 1.

As long as the above inclusion criteria are met, we will include reviews of trials in which the participants:

- have other, co-morbid, health-related problems including (but not limited to): pregnancy and delivery, cancer, neurological diseases, chronic respiratory disease, learning difficulties and dementia.

- can be recruited from any setting, including community, hospital or care home environments.

We will consider reviews which include both male and female participants, but will only include reviews in which we can extract data relating specifically to the female participants.

We will exclude reviews of surgical or pharmacological interventions, products to manage leakage of urine and investigative techniques, unless these are compared with a conservative interven- tion. We will include reviews in which a conservative intervention is considered to be a control intervention.

\section{Search methods for identification of reviews}

Relevant reviews will be identified from the Cochrane Incontinence Review Group's list of published Cochrane reviews. We will also search the Cochrane Database of Systematic Reviews (part of The Cochrane Library) using the strategy given in Appendix 1. Titles and protocols registered with the Cochrane Incontinence Review Group will also be considered.

\section{Data collection and analysis}

During the process of data collection and analysis, evidence relating to stress, urgency or mixed UI will be separated, and will be subgrouped according to these three separate groups.

The aim of this stage of the overview is on systematically bringing together assessment of methodological quality and presentation of data from the included reviews. With the exception of the final section, 'Data analysis', description of methods within subsequent sections will therefore refer to synthesis of data as presented within the included reviews, and not to any re-analysis or pooling of data.

\section{Selection of reviews}

Two independent reviewers will consider titles and abstracts from the identified reviews and apply the inclusion criteria (see Criteria for considering reviews for inclusion). If there is disagreement between reviewers, they will reach consensus through consideration and discussion of the full paper, involving a third reviewer if necessary.

We will contact authors of any titles or protocols which appear to meet our selection criteria, identifying those which authors indicate should be completed within 3 months of our initial search date. We will also contact authors of all completed reviews meeting our selection criteria for which the search date is more than 12 months ago, asking if an update is anticipated within this 3-month period. Initial contact with review authors will be made via the Cochrane Incontinence Review Group. When authors indicate that a review should be finished/updated within this timeframe, we will send reminder emails in advance of this date to check on progress, and to gain access to relevant pre-publication data where possible.

\section{Data extraction and management}

Two overview authors will extract data independently. Disagreements will be resolved by discussion, with assistance from a third overview author if necessary. We will use a data collection form specifically designed and piloted by the overview author team. 
Onto this form, we will extract and record key features of each review including details of the aims and rationale, types of studies, participants, interventions, comparisons, outcomes assessed, date of last search and meta-analyses completed.

We will systematically synthesise, using a spreadsheet, the studies included within all identified reviews to explore whether any reviews covered the same studies. When overlap between reviews is identified, two overview authors will discuss the overlap with consideration of each review question and comparisons explored, the date of the last search and key aspects of methodological quality (e.g. types of studies included, risk of bias assessment). We will use these details to reach agreement regarding which data from which review comparisons should be included within the overview.

\section{Type of UI}

During this phase of data extraction two independent reviewers will note whether each included review includes evidence relating to stress, urgency or mixed UI, or a combination thereof. We will resolve any disagreements through discussion, using a third reviewer if necessary. We will compile a list of which reviews relate to each of these three types of UI. All subsequent stages of the overview will be completed in triplicate, for:

- Conservative interventions for management of stress UI

- Conservative interventions for management of urgency UI

- Conservative interventions for management of mixed UI

We anticipate that some reviews may include populations with more than one type of UI. If separate data are available for populations with different types of UI then we will include the relevant data within the synthesis relating to stress/urgency/mixed UI. Thus one review may be included in more than one of the above groups. If a review only contains data relating to a combined population, and separate data are not available, then we will include this review within a fourth section:

- Conservative interventions for management of stress, urgency or mixed UI (combined populations)

- Unclear as some reviews do not define populations

\section{Criteria for identifying relevant comparisons}

We will use extracted data to determine which reviews have metaanalyses (comparisons) of relevance to this overview according to the three populations of women with UI (SUI, UUI, MUI). Relevant comparisons will evaluate the effect on the stated primary or secondary outcomes of interest to the overview by comparing the effects of:

1. Any conservative intervention versus control, placebo or standard care

2. Any conservative intervention versus other active intervention (i.e. surgical or pharmacological intervention)

3. One conservative intervention versus another conservative intervention
4. Comparisons of different doses, intensities or timing of delivery of conservative intervention

\section{Primary Outcomes}

The primary outcomes of interest to this overview are:

1. Condition-specific quality of life, as measured by specific instruments designed to assess the impact of UI symptoms on the life of a women, such as King's Health Questionnaire (Kelleher 1997), Incontinence Quality of Life (I-QOL) (Wagner 1996) and Bristol Female Lower Urinary Tract Symptoms (BFLUTS) questionnaire (Jackson 1996)

2. Symptomatic cure or improvement of UI, as reported by the woman (including through self-report or bladder diaries)

\section{Secondary Outcomes}

1. Participant-reported cure only, accepting the definition of cure used in the review. .

2. General quality-of-life measures (i.e. not conditionspecific), such as Short Form-36

3. Adverse effects (e.g. discomfort, soreness, pain, bleeding)

4. Measures of anxiety/depression, such as Hospital Anxiety and Depression Scale (HADS)

5. Other clinician-measured or observed outcomes (e.g. pad tests, pad weights, frequency of UI). (Note: even if reported as 'cure/improvement', clinician-based measures will be considered secondary outcomes)

6. Other participant self-report not presented as cure or improvement

7. Pelvic floor muscle strength/function (e.g. digital evaluation, pelvic floor muscle dynamometry or electromyography, vaginal squeeze pressure, perineal ultrasound)

8. Skin integrity

9. Adherence to intervention (including measures of usability/ acceptability)

10. Urodynamics (urodynamic testing) (e.g. post-void residual volume, rate of bladder emptying, detrusor pressure)

11. Socioeconomic measures (e.g. cost of intervention, economic analysis, resource implications)

12. Other

We will consider outcomes at three time periods:

1. The end of treatment

2. Up to one year after end of treatment

3. More than one year after end of treatment.

We will categorise outcomes pooled within meta-analyses as either 'immediate' (i.e. at the end of intervention) or 'follow-up', documenting and reporting within tables the timepoint of the data pooled, as reported in the included review.

We will identify information relating to all outcomes synthesised within the included reviews, but will only extract data relating to effect size from relevant meta-analyses of comparisons relating to these stated outcomes of interest. 


\section{Data extraction for relevant comparisons}

Data extracted relating to meta-analyses will include:

1. The number of trials and participants

2. The mean difference or standardised mean difference (for continuous data)

3. The risk ratio or risk difference (for binary data), with $95 \%$ confidence intervals

4. The $\mathrm{I}^{2}$ statistic for heterogeneity

Where meta-analyses include presentation of subgroup data these will also be documented. These data will be checked by a second overview author with reference to the published review.

\section{Assessment of methodological quality of included reviews}

For each relevant comparison reported in each included review, one overview author will systematically extract data on the risk of bias (as documented in the published review; ideally using the Cochrane 'Risk of bias' tool, Higgins 2011b) relating to trials within each comparison and the results of the meta-analyses performed.

\section{Quality of included reviews}

Two independent overview authors will assess the methodological quality of the included reviews using the ROBIS (Risk Of Bias In Systematic reviews) tool (Whiting 2015). ROBIS is completed in three phases: (1) Assess relevance; (2) identify concerns with the review process; and (3) judge risk of bias in the review. The second phase will include assessment of whether

- review eligibility criteria were clear, appropriate and prespecified;

- all relevant primary studies should have been identified and included in the review;

- bias may have been introduced through the data collection or risk of bias assessment processes;

- appropriate methods have been used for any meta-analyses.

All signalling questions, which are included within the ROBIS tool to help assess specific concerns about potential biases within the review, will be completed and used to help overview authors judge overall risk of bias. We will use the rating guidance published with the ROBIS tool in answering all signalling questions (Whiting 2015). We will judge the risk of bias of each review to be at low, high or unclear risk of bias. We will resolve any disagreements between independent overview authors through discussion, involving a third reviewer if necessary.

If any overview authors are authors on an included review, they will not be involved in the assessment of methodological quality of that review, and this will be done independently by two other overview authors.

The agreed responses to all ROBIS phases and judgement will be tabulated and fully reported within the overview.

\section{Quality of evidence in included reviews}

We will not reassess the quality of individual studies included within reviews but will report the quality of individual studies according to the review authors' assessment.

We will assess the quality of the evidence synthesised within each relevant comparison (i.e. all relevant meta-analyses from included reviews which pool data for one of our pre-stated primary or secondary outcomes of interest) using the GRADE (Grading of Recommendations Assessment, Development and Evaluation) approach (Guyatt 2008; Guyatt 2011a), which includes the following:

- Risk of bias due to flawed design or conduct of studies (Guyatt 2011b).

- Imprecision (e.g. when confidence intervals for treatment effect are wide) (Guyatt 2011d).

- Inconsistency (e.g. when point estimates vary widely, $\mathrm{I}^{2}$ is large) (Guyatt 2011e).

- Indirectness (e.g. variations in participants, interventions, comparisons and outcomes) (Guyatt 2011f).

- Publication bias (may be explored with the use of funnel plots and classed as 'not suspected', 'suspected', 'strongly suspected' or 'very strongly suspected') (Guyatt 2011c).

The GRADE approach provides a system for rating quality of evidence and strength of recommendations that is explicit, comprehensive, transparent, and pragmatic and is increasingly being adopted by organisations worldwide. However, difficulties associated with the subjectivity involved in judging grade of evidence has previously been reported, and poor agreement has been found on grading strength of evidence within systematic reviews using GRADE, even amongst experienced systematic reviewers (Berkman 2013). A previous Cochrane overview has reported that it was difficult to achieve agreement between independent overview authors for GRADE judgements when a large number of comparisons needed to be assessed (Pollock 2014), and proposed the use of an objective algorithm to enable transparent, reproducible assignment of GRADE levels of evidence (Pollock 2014; Pollock 2015).

The overview author team will therefore explore use of the iterative methods reported by Pollock 2015 to develop a set of objective criteria for exploring the quality of the specific body of evidence included within this overview. A consecutive sample of five reviews will be used to explore and develop a final algorithm, involving comparison of the subjective grading of evidence applied by three independent overview authors, with data generated using a draft algorithm. The draft algorithm will involve systematic assessment of:

- the number of participants within the analysis;

- the risk of bias of trials contributing participants to the analysis, as reported by the review authors within 'Risk of bias' tables;

- heterogeneity within the analysis, as determined by ${ }^{2}$; and 
- the methodological quality of the review, as determined by our ROBIS assessment.

However the iterative, exploratory process used to develop the final algorithm may lead to the addition or removal of criteria (using the methods described by Pollock 2015). We will document this process and detail the final objective algorithm. We will be guided by key publications relating to application of the GRADE framework (Guyatt 2011a).

Following agreement of the final algorithm, two overview authors will work together to ensure consensus and consistency of entry of objective data pertaining to these criteria onto a spreadsheet, and will apply the objective algorithm to determine whether evidence arising from each comparison relating to one of our pre-stated outcomes of interest was classed as 'high', 'moderate', 'low' or 'very low' within GRADE, based on the following definitions (Balshem 2011).

- High quality: We are very confident that the true effect lies close to that of the estimate of the effect.

- Moderate quality: We are moderately confident in the effect estimate: The true effect is likely to be close to the estimate of the effect, but there is a possibility that it is substantially different.

- Low quality: Our confidence in the effect estimate is limited: The true effect may be substantially different from the estimate of the effect.

- Very low quality: We have very little confidence in the effect estimate: The true effect is likely to be substantially different from the estimate of effect.

\section{Data synthesis}

As stated above, all data synthesis will be grouped and presented according to the type of UI: 1. stress, 2. urgency, 3. mixed, 4. combined populations, 5 . unclear.

We will tabulate a summary of systematic review evidence relating to all conservative interventions for UI, clearly signposting which systematic reviews address which interventions, with summary of details of the population of participants, comparisons, volume and quality of evidence. We will categorise the conservative interventions using the categories described in How the interventions might work and Figure 1. Where conservative interventions are delivered in combination we will categorise these according to the combined interventions, but clearly highlighting the individual interventions.

For each relevant intervention comparison and for both primary and secondary outcome of interest (see Data extraction and management) we will produce a 'Summary of results' table (see Table 1) clearly indicating where there is evidence of an effect of conservative interventions. In addition to this summary we will tabulate - for both primary and secondary outcomes - the number of studies and participants included in the comparison, the mean difference or standardised mean difference (for continuous data), the risk ratio or risk difference (for binary data), $95 \%$ confidence intervals, and the $\mathrm{I}^{2}$ statistic for heterogeneity. We will clearly highlight where the data indicate statistically significant evidence of benefit, harm or no effect, relating this to the assigned GRADE quality of evidence.

\section{Exploration of subgroups}

The objective of this overview is to systematically synthesise the results of data pooled within reviews relating to conservative interventions for different types of urinary incontinence. As part of this objective we plan to explore existing data relating to different subgroups of women. We do not plan to carry out any statistical subgroup comparisons ourselves. Where the included reviews have carried out subgroup analyses relating to our pre-defined subgroups (listed below), using data from one of our primary outcomes, we will extract and tabulate the results of these analyses. We will report the pooled data for all the subgroups as defined within the included reviews, and the results of the statistical test for subgroup differences.

Where possible we will synthesise data from meta-analyses of our stated primary outcomes which relates to the following pre-defined subgroups:

1. Severity of symptoms (mild/moderate/severe)

2. Pregnancy (pregnancy/no pregnancy, and antenatal/ postnatal and mode of delivery)

3. Health-related cause of UI (cancer, neurological diseases, chronic respiratory disease, learning difficulties, dementia)

4. Age (pre-menopausal/post-menopausal)

5. Co-morbidities (i.e. any other conditions)

6. BMI (normal/obese/morbidly obese)

7. Ethnicity

8. Duration of symptoms

9. Place of living (living at home, in care home or in nursing home)

10. Socio-economic status.

In addition, where possible we will synthesise data relating to groups of participants with nocturia, nocturnal enuresis and coital incontinence. Data relating to any of these subgroups will be tabulated, grouped according to intervention.

\section{Statistical analysis}

The main aim of this overview is to provide a summary of evidence relating to the effectiveness of conservative interventions for UI. Descriptive summaries of the data relating to comparisons with the included reviews will be reported.

For our three populations of interest (stress UI, urgency UI, mixed UI), and for our primary outcomes of (1) condition-specific quality of life and (2) symptomatic cure or improvement of UI, we will also:

1. Summarise the available data by creating a visual map of the direct comparisons reported by the individual trials included within 
the reviews. These network maps will illustrate the number of trials and number of participants within trials. Network maps will be created using Stata software. The mapping function available allows for weighting and colouring options for both nodes and edges in the map, which reveal important differences in the characteristics of treatments or comparisons (Chaimani 2013; Palmer 2016). For example, the nodes and edges can be weighted according to the number of studies or participants involved in each treatment and comparison respectively. These summaries will illustrate the quantity and quality of evidence for different comparisons, but are not designed to summarise effect sizes for the comparisons.

2. Perform subgroup analyses, for comparisons of intervention versus control, placebo or standard care. Subgroup analyses will only be completed following an exploration of the clinical populations included in the trials in the included reviews. Three overview authors, including a content expert, methods expert and statistician, will discuss the available data and reach consensus on whether any data are suitable for meta-analysis. The authors will consider whether the enrolment criteria to the trials of different interventions, contained within different reviews, are similar in relation to etiological factors, symptom severity, comorbidities and other relevant factors. The outcome of these discussions will be documented and reported to ensure transparency of this decision making. Where the clinical populations of trials included in reviews of different interventions are judged to be similar we will estimate the difference between the subgroups and determine its statistical significance (Higgins 2011a). The difference between the summary effects in any two given subgroups will provide an estimate of the indirect comparison of different interventions (Higgins 2011b). If possible, we will complete the following subgroup analyses, for populations of women with stress UI, urgency UI and mixed UI: a) Any conservative intervention versus control, placebo or standard care for condition-specific quality of life, with subgroups de- fined according to type of intervention. Continuous data (means, standard deviations, number of participants) relating to the effects reported by individual trials and included in relevant reviews will be extracted and entered into a subgroup analysis within Review Manager 5 or Stata, and depicted with forest plots. We will compute standardised mean differences for the different subgroups, pooling data from different condition-specific quality of life measurement scales. We will report the test for subgroup differences using an inverse-variance random-effects model for meta-analysis of continuous outcomes (Deeks 2011).

b) Any conservative intervention versus control, placebo or standard care for symptomatic cure or improvement of UI, with subgroups defined according to type of intervention. Binary counts data (number of events, number of participants) relating to the events reported by individual trials and included in relevant reviews will be extracted and entered into a subgroup analysis within Review Manager 5 or Stata, and depicted with forest plots. We will compute the relative risk for the different subgroups, and report the test for subgroup differences using the generic inverse-variance random-effects model (Deeks 2011).

\section{ACKNOWLEDGEMENTS}

We would like to thank members of a stakeholder group who contributed to discussions and consensus agreement over definition and categorisation of conservative interventions, relevant subgroups and outcomes of interest to this overview. We would like to thank the following Cochrane Incontinence editorial base staff members for their help and support with this review: Lyn Ajanaku, Chantale Dumoulin, Peter Herbison, Suzanne Macdonald, Muhammad Imran Omar, Luke Vale, and Sheila Wallace.

\section{REF ER E N C E S}

\section{Additional references}

\section{Alewijnse 2003a}

Alewijnse D, Metsemakers JF, Mesters IE, van den Borne B. Effectiveness of pelvic floor muscle exercise therapy supplemented with a health education program to promote long-term adherence among women with urinary incontinence. Neurourology and Urodynamics 2003;22(4): 284-95.

Alewijnse 2003b

Alewijnse D, Mesters I, Metsemakers J, van den Borne B. Predictors of long-term adherence to pelvic floor muscle exercise therapy among women with urinary incontinence. Health Education Research 2003;18(5):511-24.

Alhasso 2005

Alhasso A, Glazener CMA, Pickard R, N'Dow JMO.

Adrenergic drugs for urinary incontinence in adults.
Cochrane Database of Systematic Reviews 2005, Issue 3. [DOI: 10.1002/14651858.CD001842.pub2]

Alves 2015

Alves F, Riccetto C, Adami DB, Marques J, Pereira LC, Palma P, et al. A pelvic floor muscle training program in postmenopausal women. A randomized controlled trial. Maturitas 2015;81(2):300-5.

Amaro 2003

Amaro JL, Gameiro MO, Padovani CR. Treatment of urinary stress incontinence by intravaginal electrical stimulation and pelvic floor physiotherapy. International Urogynecology Journal 2003;14(3):204-8.

\section{Balshem 2011}

Balshem H, Helfand M, Schünemann HJ, Oxman AD, Kunz R, Brozek J, et al. GRADE guidelines: 3. Rating the 
quality of evidence. Journal of Clinical Epidemiology 2011; 64(4):401-6.

\section{Bastian 2010}

Bastian H, Glasziou P, Chalmers I. Seventy-five trials and eleven systematic reviews a day: how will we ever keep up?. PLoS Medicine 2010;7(9):e1000326.

Berkman 2013

Berkman ND, Lohr KN, Morgan LC, Kuo T-M, Morton SC. Interrater reliability of grading strength of evidence varies with the complexity of the evidence in systematic reviews. Journal of Clinical Epidemiology 2013;66(10): 1105-17.

Blaivas 1997

Blaivas JG, Appell RA, Fantl JA, Leach G, McGuire EJ, Resnick NM, et al. Definition and classification of urinary incontinence: recommendations of the Urodynamic Society. Neurourology and Urodynamics 1997;16(3):149-51.

Bogner 2002

Bogner HR, Gallo JJ, Sammel MD, Ford DE, Armenian HK, Eaton WW. Urinary incontinence and psychological distress in community-dwelling older adults. Journal of the American Geriatrics Society 2002;50(3):489-95.

Bump 1992

Bump RC, McClish DK. Cigarette smoking and urinary incontinence in women. American Journal of Obstetrics and Gynecology 1992;167(5):1213-8.

\section{Вø 2013}

$\mathrm{B} ø \mathrm{~K}$, Herbert R. There is not yet strong evidence that exercise regimens other than pelvic floor muscle training can reduce stress urinary incontinence in women: a systematic review. Journal of Physiotherapy 2013;59(3):159-68.

\section{Вø 2016}

Bø K, Frawley H, Haylen B, Abramov Y, Almeida F, Berghmans B, et al. An IUGA/ICS joint report on the terminology for the conservative and non-pharmacological management of female pelvic floor dysfunction (in preparation). Neurourology and Urodynamics 2016.

\section{Cadwell 1963}

Cadwell KPS. The electrical control of the sphincter incompetence. Lancet 1963;2(7300):174-5.

\section{Carriere 2006}

Carriere B. Interdependence of posture and the pelvic floor. In: Carriere B, Feldt CM editor(s). The Pelvic Floor. New York: Thieme, 2006:68-81.

\section{Chaimani 2013}

Chaimani A, Higgins JPT, Mavridis D, Spyridonos P, Salanti G. Graphical tools for network meta-analysis in STATA. PLOS ONE 2013;8(10):e76654.

\section{Chang 1986}

Chang ST. The complete system of self-healing: internal exercises. California: Tao Publishing, 1986.

\section{Chiarelli 1999}

Chiarelli P, Cockburn J. The development of physiotherapy continence promotion progrm using a customer focus. The Australian Journal of Physiotherapy 1999;45(2):111-9.

\section{Clement 2013}

Clement KD, Lapitan MCM, Omar MI, Glazener CMA. Urodynamic studies for management of urinary incontinence in children and adults. Cochrane Database of Systematic Reviews 2013, Issue 10. [DOI: 10.1002/ 14651858.CD003195.pub3]

Cody 2012

Cody JD, Jacobs ML, Richardson K, Moehrer B, Hextall A. Oestrogen therapy for urinary incontinence in post-menopausal women. Cochrane Database of Systematic Reviews 2012, Issue 10. [DOI: 10.1002/ 14651858.CD001405.pub3]

de Groat 1997 de Groat WC. A neurogenic basis for the overactive bladder. Urology 1997;50(6a Suppl):36-52.

\section{de Groat 2001}

de Groat WC, Fraser MO, Yoshiyama M, Smerin S, Tai C, Chancellor MB, et al. Neural control of the urethra. Scandinavian Journal of Urology and Nephrology Supplementum 2001;207:35-43.

Dean 2006 Dean N, Ellis G, Herbison GP, Wilson D. Laparoscopic colposuspension for urinary incontinence in women.. Cochrane Database of Systematic Reviews 2006, Issue 3. [DOI: 10.1002/14651858.CD002239.pub2]

\section{Deeks 2011}

Deeks JJ, Higgins JPT, Altman DG (editors). Chapter 9: Analysing data and undertaking meta-analyses. In: Higgins JPT, Green S (editors). Cochrane Handbook for Systematic Reviews of Interventions Version 5.1.0 [updated March 2011]. The Cochrane Collaboration, 2011. Available from www.cochrane-handbook.org.

\section{Dumoulin 2014}

Dumoulin C, Hay-Smith EJC, Mac Habée-Séguin G. Pelvic floor muscle training versus no treatment, or inactive control treatments, for urinary incontinence in women. Cochrane Database of Systematic Reviews 2014, Issue 5. [DOI: 10.1002/14651858.CD005654.pub3]

\section{Duthie 2011}

Duthie JB, Vincent M, Herbison GP, Wilson DI, Wilson D. Botulinum toxin injections for adults with overactive bladder syndrome. Cochrane Database of Systematic Reviews 2011, Issue 12. [DOI: 10.1002/ 14651858.CD005493.pub3]

\section{Eustice 2000}

Eustice S, Roe B, Paterson J. Prompted voiding for the management of urinary incontinence in adults. Cochrane Database of Systematic Reviews 2000, Issue 2. [DOI: 10.1002/14651858.CD002113]

Ford 2015

Ford AA, Rogerson L, Cody JD, Ogah J. Mid-urethral sling operations for stress urinary incontinence in women. Cochrane Database of Systematic Reviews 2015, Issue 7. [DOI: 10.1002/14651858.CD006375.pub3] 


\section{Francis 2012}

Francis AM, Madill SJ, Gentilcore-Saulnier E, McLean L. Survey of Canadian Physiotherapists: Entry-level and postprofessional education in Women's Health. Physiotherapy Canada 2012;64(3):271-9.

\section{French 2010}

French B, Thomas LH, Leathley MJ, Sutton CJ, Booth $\mathrm{J}$, Brittain $\mathrm{K}$, et al. Combined conservative interventions for urge, stress or mixed incontinence in adults. Cochrane Database of Systematic Reviews 2010, Issue 12. [DOI: 10.1002/14651858.CD008910]

\section{Glazener 2001}

Glazener CMA, Cooper K. Anterior vaginal repair for urinary incontinence in women. Cochrane Database of Systematic Reviews 2001, Issue 1. [DOI: 10.1002/ 14651858.CD001755]

\section{Glazener 2014}

Glazener CMA, Cooper K. Bladder neck needle suspension for urinary incontinence in women. Cochrane Database of Systematic Reviews 2014, Issue 12. [DOI: 10.1002/ 14651858.CD003636.pub3]

\section{Godec 1975}

Godec C, Cass AS, Ayala GF. Bladder inhibition with functional electrical stimulation. Urology 1975;6(6):663-6.

\section{Groutz 2000}

Groutz A, Blaivas JG, Chaikin DC, Resnick NM, Engleman $\mathrm{K}$, Anzalone D, et al. Noninvasive outcome measures of urinary incontinence and lower urinary tract symptoms: A multicenter study of micturition diary and pad tests. Journal of Urology 2000;164(3):698-701.

\section{Guyatt 2008}

Guyatt GH, Oxman AD, Vist G, Kunz R, Falck-Ytter Y, et al. GRADE Working Group. Rating quality of evidence and strength of recommendations GRADE: an emerging consensus on rating quality of evidence and strength of recommendations. BMJ 2008;336(7650):924-6.

\section{Guyatt 2011a}

Guyatt GH, Oxman AD, Schünemann HJ, Tugwell P, Knotterus A. GRADE guidelines: A new series of articles in the Journal of Clinical Epidemiology. Journal of Clinical Epidemiology 2011;64(4):380-2.

\section{Guyatt 2011b}

Guyatt GH, Oxman AD, Vist G, Kunz R, Brozek J, AlonsoCoello P, et al. GRADE guidelines: 4. rating the quality of evidence - risk of bias. Journal of Clinical Epidemiology 2011;64(4):407-15.

\section{Guyatt 2011c}

Guyatt GH, Oxman AD, Montori V, Vist G, Kunz R, Brozek J, et al. GRADE guidelines: 5. rating the quality of evidence - publication bias. Journal of Clinical Epidemiology 2011;64(12):1277-82.

\section{Guyatt 2011d}

Guyatt G, Oxman AD, Kunz R, Brozek J, Alonso-Coello P, Rind D, et al. GRADE guidelines: 6 . Rating the quality of evidence - imprecision. Journal of Clinical Epidemiology 2011;12:1283-93.

\section{Guyatt 2011e}

Guyatt GH, Oxman AD, Kunz R, Woodcock J, Brozek J, et al. The GRADE Working Group. GRADE guidelines:

7. Rating the quality of evidence - inconsistency. Journal of Clinical Epidemiology 2011;64(12):1294-1302.

\section{Guyatt 2011f}

Guyatt GH, Oxman AD, Kunz R, Woodcock J, Brozek J, et al. The GRADE Working Group. GRADE guidelines:

8. Rating the quality of evidence - indirectness. Journal of Clinical Epidemiology 2011;64(12):1294-302.

\section{Hajebrahimi 2015}

Hajebrahimi S, Sadeghi-Bazargani H, Taleschian Tabrizi N, Farhadi F, Sadeghi Ghyassi F. Non-drug treatment for lower urinary tract symptoms in women with voiding dysfunction. Cochrane Database of Systematic Reviews 2015, Issue 1. [DOI: 10.1002/14651858.CD011470]

\section{Haylen 2010}

Haylen R, de Ridder D, Freeman R, Swift SE, Berghmans $\mathrm{B}$, Lee J, et al. An International Urogynecological Association (IUGA)/International Continence Society (ICS) Joint Report on the Terminology of Female Pelvic Floor Dysfunction.. Neurourology and Urodynamics 2010; 29(1):4-20.

\section{Herbison 2013}

Herbison GP, Dean N. Weighted vaginal cones for urinary incontinence. Cochrane Database of Systematic Reviews 2013, Issue 7. [DOI: 10.1002/14651858.CD002114.pub2]

\section{Higgins 2011a}

Higgins JPT, Green S (editors). Cochrane Handbook for Systematic Reviews of Interventions Version 5.1.0 [updated March 2011]. The Cochrane Collaboration, 2011. Available from www.cochrane-handbook.org.

\section{Higgins 2011b}

Higgins JPT, Deeks JJ, Altman DG (editors). Chapter 16: Special topics in statistics. In: Higgins JPT, Green S (editors), Cochrane Handbook for Systematic Reviews of Interventions Version 5.1.0 (updated March 2011). The Cochrane Collaboration, 2011. Available from www.cochrane-handbook.org.

\section{Hunskaar 2002}

Hunskaar S, Burgio K, Diokno AC, Herzog AR, Hjalmas K, Lapitan MC. Epidemiology and natural history of urinary incontinence. In: Abrams P, Cardozo L, Khoury S, Wein A editor(s). Incontinence. 2nd Edition. Health Publication Ltd, 2002.

\section{Hunskaar 2005}

Hunskaar S, Burgio K, Clark A, Lapitan MC, Nelson $\mathrm{R}$, Sillén $\mathrm{U}$, et al. Epidemiology of urinary and faecal incontinence and pelvic organ prolapse. In: Abrams P, Cardozo L, Khoury R, Wein A editor(s). Incontinence. 3rd International Consultation on Incontinence. Plymouth, UK: Health Publication Ltd, 2005:255-312. 


\section{Imamura 2015}

Imamura M, Williams K, Wells M, McGrother C. Lifestyle interventions for the treatment of urinary incontinence in adults. Cochrane Database of Systematic Reviews 2015, Issue 12. [DOI: $10.1002 / 14651858 . C D 003505 . p u b 5]$

\section{Islah 2013}

Islah M, Cho SY, Son H. The current role of the artificial urinary sphincter in male and female urinary incontinence. The World Journal of Men's Health 2013;31(1):21-30.

\section{Jackson 1996}

Jackson S, Donovan J, Brookes S, Eckford S, Swithinbank L, Abrams P. The Bristol Female Lower Urinary Tract Symptoms questionnaire: development and psychometric testing. British Journal of Urology 1996;77(6):805-12.

\section{Kelleher 1997}

Kelleher CJ, Cardozo LD, Khullar V, Salvatore S. A new questionnaire to assess the quality of life of urinary incontinent women. British Journal of Obstetrics and Gynaecology 1997;104(12):1374-9.

\section{Kirchin 2012}

Kirchin V, Page T, Keegan PE, Atiemo K, Cody JD, McClinton S. Urethral injection therapy for urinary incontinence in women. Cochrane Database of Systematic Reviews 2012, Issue 2. [DOI: 10.1002/ 14651858.CD003881.pub3]

\section{Komesu 2011}

Komesu YM, Sapien RE, Rogers RG, Ketai LH. Hypnotherapy for treatment of overactive bladder: a randomized controlled trial pilot study. Female Pelvic Medicine and Reconstructive Surgery 2011;17(6):308-13. [DOI: 10.1097/SPV.0b013e31823a08d9]

\section{Lapitan 2016}

Lapitan MCM, Cody JD. Open retropubic colposuspension for urinary incontinence in women. Cochrane Database of Systematic Reviews 2016, Issue 2. [DOI: 10.1002/ 14651858.CD002912.pub6]

\section{Lipp 2014}

Lipp A, Shaw C, Glavind K. Mechanical devices for urinary incontinence in women. Cochrane Database of Systematic Reviews 2014, Issue 12. [DOI: 10.1002/ 14651858.CD001756.pub6]

\section{MacArthur 1993}

MacArthur C, Lewis M, Bick D. Stress incontinence after childbirth. British Journal of Midwifery 1993;1(5):207-15.

\section{McClurg 2013}

McClurg D, Cheater FM, Eustice S, Burke J, Jamieson K, Hagen S. A multi-professional UK wide survey of undergraduate continence education. Neurourology and Urodynamics 2013;32(3):224-9.

\section{Melville 2009}

Melville JL, Fan MY, Rau H, Nygaard IE, Katon WJ. Major depression and urinary incontinence in women: temporal associations in an epidemiologic sample. American Journal of Obstetrics and Gynecology 2009;201(490):e1-7.

\section{Messelink 1999}

Messelink EJ. The overactive bladder and the role of pelvic floor muscles. British Journal of Urology 1999;83(Suppl 2): $31-5$.

\section{Milsom 2012}

Milsom I, Altman D, Cartwright R, Lapitan MC, Nelson $\mathrm{R}$, Sillén $\mathrm{U}$, et al. Epidemiology of urinary incontinence (UI) and other lower urinary tract symptoms (LUTS), pelvic organ prolapse (POP) and anal incontinence (AI). Incontinence. ICUD-EAU, 2013.

\section{Morrill 2007}

Morrill M, Lukacz ES, Lawrence JM, Nager CW, Contreras R, Luber KM. Seeking healthcare for pelvic floor disorders: a population-based study. American Journal of Obstetrics and Gynecology 2007;197(1):86.

\section{Morrison 1995}

Morrison JFB. The excitability of the micturition reflex. Scandinavian Journal of Urology and Nephrology Supplementum 1995;175:21-5.

\section{NICE 2013}

National Institute for Healthcare and Excellence. The management of urinary incontinence in women. NICE clinical guideline 1712013.

\section{Ostaszkiewicz 2004a}

Ostaszkiewicz J, Chestney T, Roe B. Habit retraining for the management of urinary incontinence in adults. Cochrane Database of Systematic Reviews 2004, Issue 2. [DOI: 10.1002/14651858.CD002801.pub2]

\section{Ostaszkiewicz 2004b}

Ostaszkiewicz J, Johnston L, Roe B. Timed voiding for the management of urinary incontinence in adults. Cochrane Database of Systematic Reviews 2004, Issue 1. [DOI: 10.1002/14651858.CD002802.pub2]

Palmer 2016

Palmer TM, Sterne JAC (Eds). Meta-Analysis in Stata: An updated collection from the Stata journal. 2nd Edition. College Station, TX: Stata Press, 2016.

\section{Perry 2000}

Perry S, Shaw C, Assassa P, Dallosso H, Williams K, Brittain KR, et al. An epidemiological study to establish the prevalence of urinary symptoms and felt need in the community: the Leicestershire MRC Incontinence Study. Journal of Public Health Medicine 2000;22(3):427-34.

\section{Pollock 2014}

Pollock A, Farmer SE, Brady MC, Langhorne P, Mead GE, Mehrholz J, et al. Interventions for improving upper limb function after stroke. Cochrane Database of Systematic Reviews 2014, Issue 11. [DOI: 10.1002/ 14651858.CD010820.pub2]

\section{Pollock 2015}

Pollock A, Farmer SE, Brady MC, Langhorne P, Mead GE, Mehrholz J, et al. An algorithm was used to assign GRADE levels of evidence to comparisons within systematic reviews. Journal of Clinical Epidemiology 2015 Sep 01 [Epub ahead of print]. 
Rai 2012

Rai BP, Cody JD, Alhasso A, Stewart L. Anticholinergic drugs versus non-drug active therapies for non-neurogenic overactive bladder syndrome in adults. Cochrane Database of Systematic Reviews 2012, Issue 12. [DOI: 10.1002/ 14651858.CD003193.pub4]

Rehman 2011

Rehman H, Bezerra CCB, Bruschini H, Cody JD. Traditional suburethral sling operations for urinary incontinence in women. Cochrane Database of Systematic Reviews 2011, Issue 1. [DOI: 10.1002/ 14651858.CD001754.pub3]

\section{Sandvik 2000}

Sandvik H, Seim A, Vanvik A, Hunskaar S. A severity index for epidemiological surveys of female urinary incontinence: comparison with 48-hour pad-weighing tests. Neurourology and Urodynamics 2000;19(2):137-45.

Sandweiss 1985

Sandweiss JH, Wolf SL. Biofeedback and Sports Science. New York: Plenum Press, 1985.

Shinohara 2013

Shinohara K, Honyashiki M, Imai $\mathrm{H}$, Hunot V, Caldwell DM, Davies P, et al. Behavioural therapies versus other psychological therapies for depression. Cochrane Database of Systematic Reviews 2013, Issue 10. [DOI: 10.1002/ 14651858.CD008696.pub2]

Smith 2006

Smith CA, Collins CT, Cyna AM, Crowther CA. Complementary and alternative therapies for pain management in labour. Cochrane Database of Systematic Reviews 2006, Issue 4. [DOI: 10.1002/ 14651858.CD003521.pub2]

\section{Takahashi 2003}

Takahashi S, Kitamura T. Overactive bladder: magnetic versus electrical stimulation. Current Opinion in Obstetrics and Gynecology 2003;15(5):429-33.

Thom 1997

Thom DH, van den Eeden SK, Brown JS. Evaluation of parturition and other reproductive variables as risk factors for urinary incontinence in later life. Obstetrics \& Gynecology 1997;90(6):983-9.

Turner 2004

Turner DA, Shaw C, McGrother CW, Dallosso HM, Cooper NJ, MRC Incontinence Team. The cost of clinically significant urinary storage symptoms for community dwelling adults in the UK. BJU International 2004;93(9): 1246-52.

\section{Wagner 1996}

Wagner TH, Patrick DL, Bavendam TG, Martin ML, Buesching DP. Quality of Life of persons with urinary incontinence: development of a new measure. Urology 1996;47(1):67-71.

\section{Wallace 2004}

Wallace SA, Roe B, Williams K, Palmer M. Bladder training for urinary incontinence in adults. Cochrane Database of Systematic Reviews 2004, Issue 1. [DOI: 10.1002/ 14651858.CD001308.pub2]

Wang 2013

Wang Y, Zhishun L, Peng W, Zhao J, Liu B. Acupuncture for stress urinary incontinence in adults. Cochrane Database of Systematic Reviews 2013, Issue 7. [DOI: 10.1002/ 14651858.CD009408.pub2]

\section{Whitford 2011}

Whitford HM, Jones M. An exploration of the motivation of pregnant women to perform pelvic floor exercises using the revised theory of planned behavior. British Journal of Health Psychol Internet. 2011;16(4):761-78.

\section{Whiting 2015}

Whiting P, Savovic J, Higgins JP, Caldwell DM, Reeves BC, et al. ROBIS group. ROBIS: A new tool to assess risk of bias in systematic reviews was developed. Journal of Clinical Epidemiology 2015 Jun 16 [E-pub ahead of print].

Wilks 2007

Wilks J. The Bowen Techniques: the inside story. Sherborne: CYMA Ltd, 2007. [ISBN: 9780955706301]

\section{Wilson 1996}

Wilson PD, Herbison RM, Herbison GP. Obstetric practice and the prevalence of urinary incontinence three months after delivery. British Journal of Obstetrics and Gynaecology 1996;103(2): 154-61.

Yau 2006

Yau, K, Mak, HL, Cheon WC, Wong T, Liu YS, Tong, WM. Effects of Foot Reflexology on Patients with Symptomatic Idiopathic Detrusor Overactivity. International Urogynecology Journal and Pelvic Floor Dysfunction 2006;18(6):653-8.

* Indicates the major publication for the study 
ADDITIONAL TABLES

Table 1. Summary of results

\begin{tabular}{|c|c|c|c|}
\hline & Important difference & $\begin{array}{l}\text { Small difference (may not be } \\
\text { important) }\end{array}$ & Little or no difference \\
\hline High certainty evidence & $\begin{array}{l}\text { INTERVENTIONS } \\
\text { (insert list) which improve/de- } \\
\text { crease/prevents OUTCOME }\end{array}$ & $\begin{array}{l}\text { INTERVENTIONS (insert } \\
\text { list) which improves slightly/de- } \\
\text { creases slightly OUTCOME }\end{array}$ & $\begin{array}{l}\text { INTERVENTIONS (insert } \\
\text { list) which results in little or no } \\
\text { difference in OUTCOME }\end{array}$ \\
\hline Moderate certainty evidence & $\begin{array}{l}\text { INTERVEN- } \\
\text { TIONS (insert list) which prob- } \\
\text { ably improve/decrease/prevents } \\
\text { OUTCOME }\end{array}$ & $\begin{array}{l}\text { INTERVEN- } \\
\text { TIONS (insert list) which prob- } \\
\text { ably improves slightly/decreases } \\
\text { slightly OUTCOME }\end{array}$ & $\begin{array}{l}\text { INTERVENTIONS } \\
\text { (insert list) which probably re- } \\
\text { sults in little or no difference in } \\
\text { OUTCOME }\end{array}$ \\
\hline Low certainty evidence & $\begin{array}{l}\text { INTERVENTIONS } \\
\text { (insert list) which may improve/ } \\
\text { decrease/prevents OUTCOME }\end{array}$ & $\begin{array}{l}\text { INTERVENTIONS } \\
\text { (insert list) which may improve } \\
\text { slightly/decrease slightly OUT- } \\
\text { COME }\end{array}$ & $\begin{array}{l}\text { INTERVENTIONS (insert } \\
\text { list) which may result in little or } \\
\text { no difference in OUTCOME }\end{array}$ \\
\hline
\end{tabular}

Very low certainty evidence It is uncertain whether INTERVENTIONS (insert list) improves/decreases/prevents OUTCOME because the certainty of the evidence is low

No data or no studies OUTCOME was not measured or not reported or no studies were found that evaluated the impact of INTERVENTION on OUTCOME

Draft summary of results table. Separate summary of results tables are planned for each of the stated primary and secondary outcomes of interest to this overview.

(Table adapted from presentation by A Oxman at Cochane Meeting, Athens, May 2015).

\section{A P P E N DICES}

\section{Appendix I. Cochrane Database of Systematic Reviews search strategy}

[this strategy will be finalised once this approach has been OKed by CEU]

The Cochrane Database of Systematic Reviews will be searched from inception to the most recent issue using the following search strategy:

\#1 incontinen*:ti,ab,kw (Word variations have been searched)

\#2 continen*:ti,ab,kw (Word variations have been searched)

\#3 MeSH descriptor: [Urinary Bladder, Overactive] explode all trees

\#4 MeSH descriptor: [Urinary Bladder, Neurogenic] explode all trees

\#5 MeSH descriptor: [Urinary Incontinence] explode all trees

\#6 ((bladder or detrusor or vesic*) near/2 (hyper* or overactiv*)) .ti,ab,kw.

\#7 urin* near/2 (leak* or freq* or urge*) .ti,ab,kw.

Conservative interventions for urinary incontinence in women: an Overview of Cochrane systematic reviews (Protocol)

Copyright @ 2016 The Cochrane Collaboration. Published by John Wiley \& Sons, Ltd. 
\#8 ((bladder or detrusor or vesic*) near/5 (instab* or stab* or unstab* or irritab* or hyperreflexi* or dys*ynerg* or dyskinesi* or irritat*)) .ti,ab,kw.

\#9 (bladder\$ near/2 (neuropath* or neurogen* or neurolog*)) .ti,ab,kw.

\#10 (pollakisur* or pollakiur*) .ti,ab,kw.

$\# 11 \# 1$ or \#2 or \#3 or \#4 or \#5 or \#6 or \#7 or \#8 or \#9 or \#10

\section{CONTRIBUTIONS OFAUTHORS}

Doreen McClurg - Contribute to methodological decisions, and provide content expertise. Assess reviews for inclusion. Act as 3rd reviewer for disagreements during data extraction, and quality assessment. Contribute to decision making over assessment of quality of evidence within reviews. Write discussion and conclusion. Read and comment on all drafts of overview.

Alex Pollock - Write protocol. Contribute to methodological decisions. Act as 3rd reviewer for disagreements during data extraction, and quality assessment. Contribute to decision making over assessment of quality of evidence within reviews. Data synthesis. Write methods and results.

Pauline Campbell - Contribute to methodological decisions. Run searches, manage search results. Assess quality of reviews using ROBIS and quality of evidence within reviews using agreed approach to GRADE. Contribute to writing of methods and results.

Christine Hazelton - Data extraction and management. Assess quality of reviews using ROBIS and quality of evidence within reviews using agreed approach to GRADE. Data entry. Contribute to writing of results.

Andrew Elders - Lead discussion and decision relating to completion of statistical analysis. Provide advice relating to extraction of metaanalysis data. Carry out statistical analysis. Read and comment on all drafts of overview.

Suzanne Hagen - Contribute to methodological and statistical decisions, and provide content expertise. Assess reviews for inclusion. Act as 3rd reviewer for disagreements during data extraction, and quality assessment. Contribute to decision making over assessment of quality of evidence within reviews. Read and comment of all drafts of overview.

\section{DECLARATIONSOF INTEREST}

The work presented here represents the views of the overview authors and not necessarily those of the funding bodies.

\section{SOURCES OF SUPPORT}

\section{Internal sources}

- No sources of support supplied

\section{External sources}

- Physiotherapy Research Foundation, UK.

This overview was supported by a project grant by the Physiotherapy Research Foundation. This covered the salary costs of Christine Hazelton.

- Chief Scientist Office, UK.

The Nursing, Midwifery and Allied Health Professions (NMAHP) Research Unit is supported by the Chief Scientist Office of the Scottish Government.

- National Institute for Health Research, UK.

This project was supported by the National Institute for Health Research, via Cochrane Infrastructure, Cochrane Programme Grant or Cochrane Incentive funding to the Incontinence Group. The views and opinions expressed therein are those of the authors and do not necessarily reflect those of the Systematic Reviews Programme, NIHR, NHS or the Department of Health.

Conservative interventions for urinary incontinence in women: an Overview of Cochrane systematic reviews (Protocol) 